Article

\title{
Development of a New Forced Cooling Technology Using a High-Pressure Coolant for Machining Difficult-To-Machine Materials
}

\author{
Ikuo Tanabe ${ }^{1, *}$ and Hideo Hoshino ${ }^{2}$ \\ 1 Department of Mechanical Engineering, Nagaoka University of Technology, Nagaoka 940-2188, Japan \\ 2 Center for Integrated Technology Support, Nagaoka University of Technology, Nagaoka 940-2188, Japan; \\ hoshino@mech.nagaokaut.ac.jp \\ * Correspondence: tanabe@mech.nagaokaut.ac.jp; Tel.: +81-258-47-9727
}

Received: 9 May 2018; Accepted: 6 June 2018; Published: 12 June 2018

\begin{abstract}
In recent years, titanium and nickel alloys have become relevant in the production of aeronautic and astronautic parts. Since both nickel and titanium alloys have a very small thermal conductivity, the used tool will suffer huge damage from the heat generated during a grinding process. Therefore, there is a requirement for a durable tool with excellent cooling capacity. In this research, a new forced cooling technology that uses high-pressure coolant for machining difficult-to-machine materials was developed and evaluated. Here, a through hole on the rake face near the turning tool tip was machined by electrical discharge machining. Then, high-pressure coolant was supplied to the turning tool from the machined hole. Several values of pressure were experimentally performed. It is concluded from the results that the technology could effectively cool the area near the tip of a turning tool, and that the chip was also effectively removed by the high-pressure coolant.
\end{abstract}

Keywords: forced cooling; cutting; difficult-to-machine materials; coolant

\section{Introduction}

Recently, titanium and nickel alloys have become relevant as they are widely used as aircraft materials. Moreover, methods to achieve a high-precision machining of these materials have been studied [1-3]. However, these materials have low thermal conductivity causing most of the heat generated during machining to be conducted to the tool. This causes the vicinity of the tool tip to become hot, leading to potential failure of the tool due to affected hardness and mechanical strength. Thus, an effective cooling technique, such as forced cooling, against it is desired. To this end, high-pressure-coolant-aided machining has been researched since the 1950s [4]. Moreover, optimization of conventional high-pressure coolant machining of difficult-to-machine materials has been widely performed, and alternative cooling methods such as cryogenic machining are currently being explored [5-9]. In the same way, extensive discussion of the usage of MQL as an environmentally-friendly alternative to flooded coolant environments has also been presented in compilations that are readily available [9]. From this, it has been observed that high-pressure or jet coolant streams are an option to alter the thermal behavior near the machining zone, including both neat oils and water-soluble oils, and provide an improved tool-life through changes in chip geometry and breakability, friction interactions and other parameters [9]. On the other hand, supply of high-pressure coolant has been mostly focused on positioning coolant outlets on the tool and near the machining zone [10]. This has been observed to be optimized to alter most of the cutting zone thermal behavior (e.g., coolant internally supplied through the tool shank straight into the cutting zone by nearby outlets) $[9,10]$. It has also been presented that internally supplying coolant from the insert instead 
of just supplying it in the cutting zone vicinity could be possible during machining (i.e., parting-off operations) [11].

Therefore, it was thought that internally supplying coolant through the insert or cutting tool could be an alternative in heavy-duty machining conditions of hard-to-machine materials (e.g., turning operations). In this research, a new forced cooling technology that uses high-pressure coolant internally supplied from the cutting tool for the machining of difficult-to-machine materials during turning was developed and evaluated. Here, for the manufacturing of said cutting tool, a through hole on the rake face near the tip of a turning tool was machined by electrical discharge machining. Then, high-pressure coolant was supplied to the turning tool from the machined hole. Particularly, this method proposes an alternative to conventional methods that do not necessarily reach the tool tip-chip interface which is the main relevant area during cutting. This method was thought to have the following benefits by suppressing the contact of the tool rake face and the chip as shown in Figure 1: (1) suppression of frictional heat generated between the tool rake face and chip; (2) suppression of frictional heat conduction to the tool; and (3) efficient forced cooling near the tool tip. In order to verify this, experimentation was carried out by mounting the proposed tool on a vertical lathe and cutting Ti6Al4V workpieces. Here, tool temperature, tool life, and chip geometry measurements were conducted and evaluated.

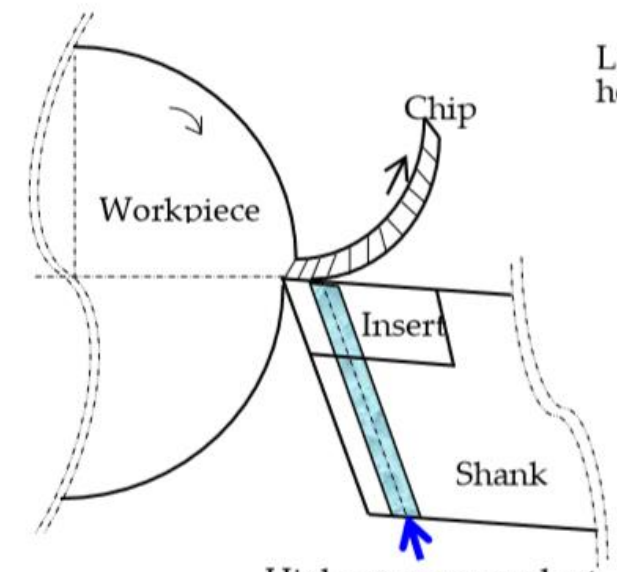

High-pressure coolant

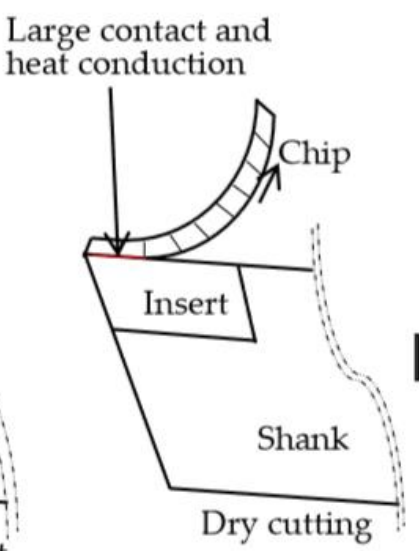

Dry cutting
Small contact and heat conduction

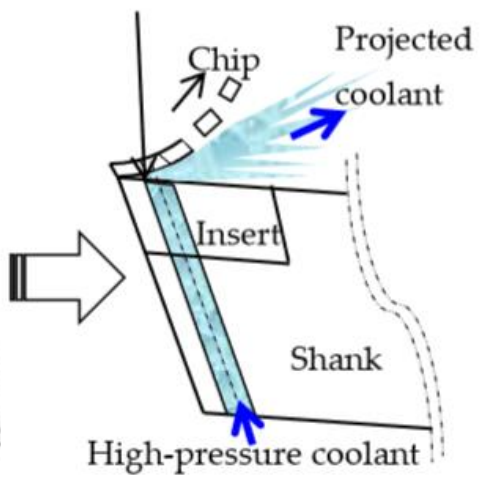

(a) Proposed forced cooling with high-pressure coolant

(b) Generated chip behavior

Figure 1. Schematics of the proposed forced cooling method with high-pressure coolant.

\section{Evaluation of the Proposed Forced Cooling Method}

\subsection{Proposed Forced Cooling Method in a Vertical Lathe}

Turning was carried out by mounting the proposed forced cooling device on a vertical lathe, and its cooling effect was evaluated. Here, Figure 2 shows a photograph of the vertical lathe and the workpiece used in the experimental section, and Table 1 shows the specifications and cutting conditions of the vertical lathe. The aforementioned machining conditions, tool temperature, and tool life were measured to evaluate the cooling effects of the proposed machining system by comparing dry cutting, conventional wet cutting with high-pressure coolant, and the proposed wet cutting method. The pressure of the coolant to be supplied through the hole machined over the insert rake face was used as an experimental parameter, and the conditions with the best forced cooling effect were selected in the next section. However, in the case of the conventional cutting fluid the coolant pressure was set at $8 \mathrm{MPa}$ with a flow of $0.5 \ell / \mathrm{min}$, which are the commercially recommended parameters for this turning operation. Both wet cutting methods utilized a JIS A1 water-soluble emulsion as the cutting fluid. Finally, the workpieces used were of Ti6Al4V alloy and the inserts used were tungsten carbide inserts. Here, the electrical discharge machining operation was ordered according to the insert material. 


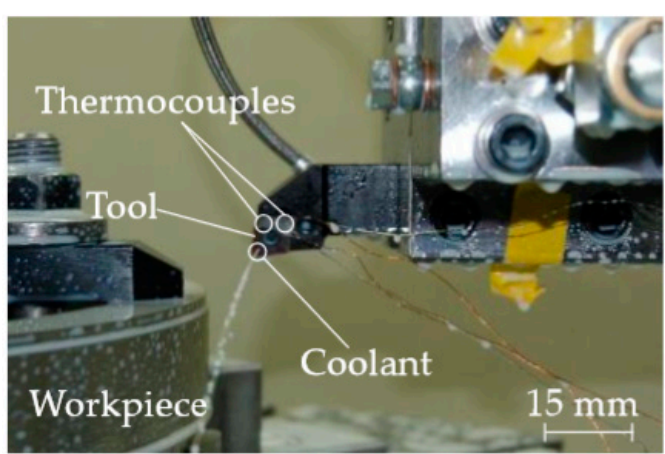

(a) Tool with high-pressure coolant

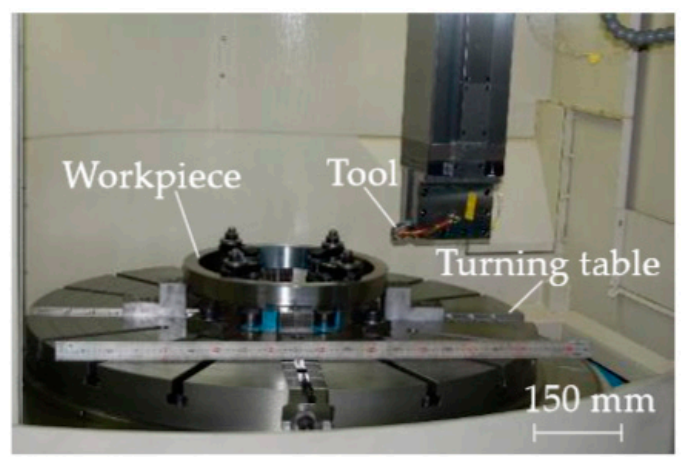

(b) Schematic view of machining area

Figure 2. Vertical lathe used for experimentation.

Table 1. Specification of vertical lathe and cutting conditions used in the experiment.

\begin{tabular}{|c|c|c|}
\hline 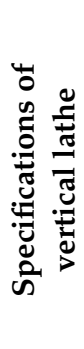 & $\begin{array}{c}\text { Table diameter } \\
\text { Max. turning diameter } \\
\text { Max. mass of workpiece } \\
\text { Max. cutting torque } \\
\text { Vertical travel of ram } \\
\text { Max. feed speed } \\
\text { Main motor } \\
\text { Max. height of machine } \\
\text { Floor space }\end{array}$ & $\begin{array}{c}1100 \mathrm{~mm} \\
1250 \mathrm{~mm} \\
3000 \mathrm{~kg} \\
10,000 \mathrm{~N} \cdot \mathrm{m} \\
800 \mathrm{~mm} \\
500 \mathrm{~mm} / \mathrm{rev} \\
30 \mathrm{~kW} \\
3790 \mathrm{~mm} \\
3955 \times 3840 \mathrm{~mm}\end{array}$ \\
\hline 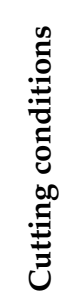 & $\begin{array}{l}\text { Workpiece material } \\
\text { Insert type } \\
\text { Depth of cut } \\
\text { Feed speed } \\
\text { Cutting speed } \\
\text { Cooling fluid } \\
\text { Fluid pressure } \\
\text { Quantity of flow }\end{array}$ & $\begin{array}{c}\text { Ti-6Al-4V } \\
\text { Tungsten Carbide } \\
1.0 \mathrm{~mm} \\
0.8 \mathrm{~mm} / \mathrm{rev} \\
60 \mathrm{~m} / \mathrm{min} \\
\text { JIS A1 cutting fluid emulsion } \\
1,8,20 \mathrm{MPa} \\
0.5 \ell / \mathrm{min}\end{array}$ \\
\hline
\end{tabular}

These processing conditions were thought to be capable of reliably lifting up the generated chips from beneath while maintaining the strength of the tool by force cooling the machining zone. This was thought to be highly relevant since calculations based on cutting theory under the aforementioned processing conditions and a feed speed of $0.8 \mathrm{~mm} / \mathrm{min}$ show extreme thermal conditions [11,12]. For instance, the heat input to the tool on a dry machining operation would be $150 \mathrm{~W}$ and the tool tip temperature would reach $2271{ }^{\circ} \mathrm{C}$ in this case, which highly risks the strength integrity of the tool. Moreover, if the feed speed is changed to $0.2 \mathrm{~mm} / \mathrm{min}$, the tool tip temperature would reach $1192{ }^{\circ} \mathrm{C}$. Consequently, areas of the cutting zone that might not be reachable under conventional high-pressure coolant delivery techniques need to be addressed through forced cooling methods similar to the proposed system. The current study attempts only to study the cooling effects of a new coolant delivery method and uses a conventional JIS-defined emulsion coolant. Thus, this paper does not cover highly-relevant areas for the machining of difficult-to-machine materials such as the usage of alternative coolants that might address thermal alleviation and equipment water-caused corrosion (e.g., strong alkaline water or microbubble-infused strong alkaline water) [13-16].

\subsection{Tool Temperature Evaluation}

The Ti6Al4V workpieces were cut under the cutting conditions shown in Table 1, and the tool temperature at that time was measured. Here, Figure 3a shows the temperature-measuring thermocouple located in the vicinity of the cutting tool tip (Point A). It must be noted that the 
temperature measurement in the case of conventional wet cutting was difficult given that the coolant delivery method applied coolant directly onto this point. However, it can be argued that, by comparing it to dry cutting, the proposed method forced cooling effect is large given that the temperature increase at Point $\mathrm{A}$ after $30 \mathrm{~s}$ was of about $5{ }^{\circ} \mathrm{C}$ while the cooling delivery method supplied coolant closer to the tool tip. Figure $3 \mathrm{~b}$ shows the results of an inverse analysis procedure that used the experimental values of Figure 3a together with FEM (Finite Element Method) analysis. Particularly, these results were extrapolated through an FEM-based inverse analysis that used two different points (Point A and Point B) near the tool tip to estimate the temperature [17]. In the case of conventional wet cutting, it was difficult to extrapolate the tool tip temperature for the reasons previously presented. From Figure $3 b$, it was possible to observe that an increase in pressure leads to an improved cooling capacity.

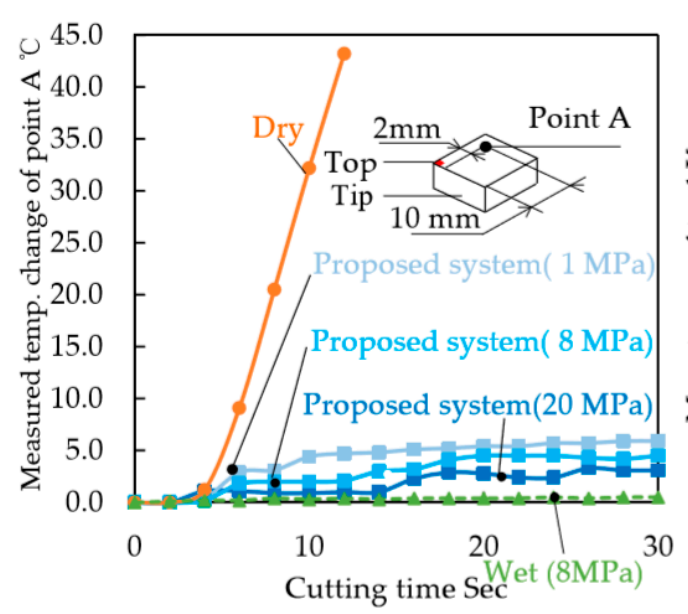

(a) Measured temperatures around tip

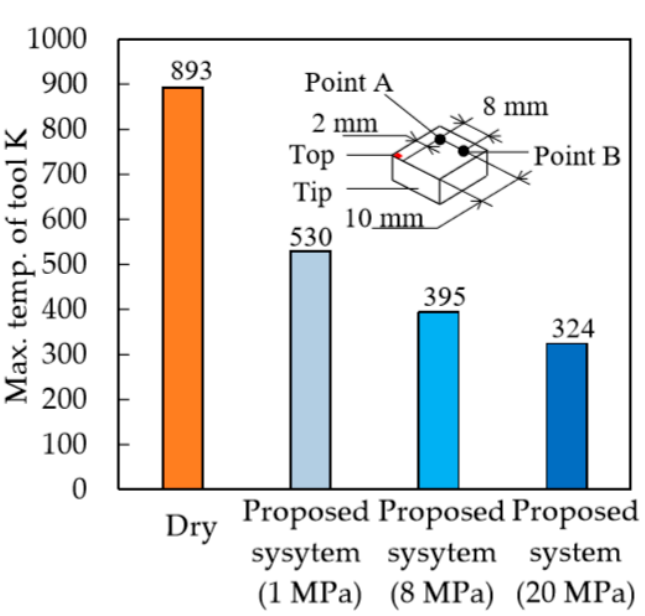

(b) Influence of pressure

Figure 3. Temperature change on the tool using high-pressure coolant (In the case of Ti6Al4V).

\subsection{Tool-Life Evaluation}

The tool life using the proposed forced cooling method was evaluated with the same cutting conditions (Table 1) as in the previous section. Here, the same three types of cutting-dry cutting, conventional wet cutting, and the proposed wet cutting-were analyzed utilizing Ti6Al4V workpieces. For this, tool-life was set to be defined as the increase in the tool flank wear and Figure 4 shows the results of the tool life test. It must be noted that, for this research, rake face wear was not analyzed due to the aforementioned standard definition. Here, it can be observed that in the case of the wet cutting (20 MPa) proposed in this report, the tool life was increased by about 10.2 times when compared to dry cutting, while the tool life was increased by about 2.7 times when compared to conventional wet cutting ( $8 \mathrm{MPa})$. This was considered to be the result of considerably suppressing the decrease in the hardness of the tool due to temperature rise and maintaining the tool rigidity [18].

Finally, Figure 5 shows both the generated chip on the presented turning operation and the resultant flank tool wear at the tool-life limit of each of the selected cutting regimes. From the Figure, it can be seen that the proposed wet cutting considerably reduces the flank tool wear when compared with the other cutting regimes at much lower cutting volumes. Moreover, it was observed that the proposed tool did not present cracks near the machined hole. On the other hand, in terms of chip geometry, the chip breaking function of the conventional wet cutting method was confirmed to be present. Even with the wet cutting proposed in this report, sufficient chip breaking function was demonstrated at a $20 \mathrm{MPa}$ coolant pressure. In addition, chips generated with the proposed wet cutting (20 MPa) were observed to present intermittent bended sections. This was thought to be a deformation of the chip above the tool rake surface caused by the high-pressure coolant supplied from the machined coolant hole during cutting, which effectively had a lifting effect. 


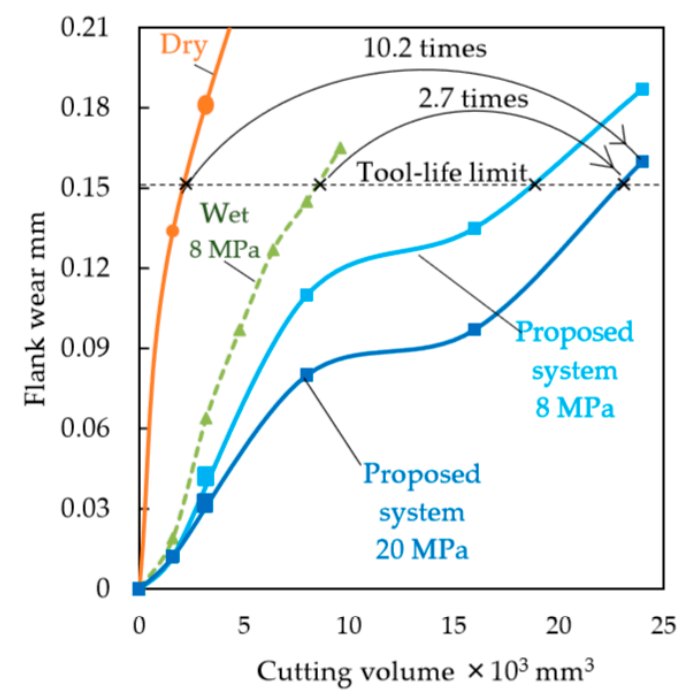

Figure 4. Experimental results of tool-life test.

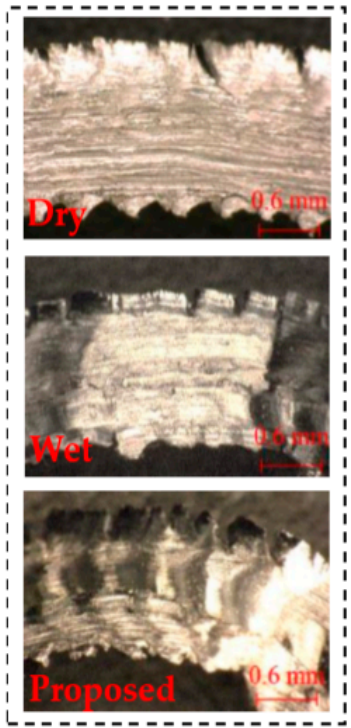

(a) Generated chip

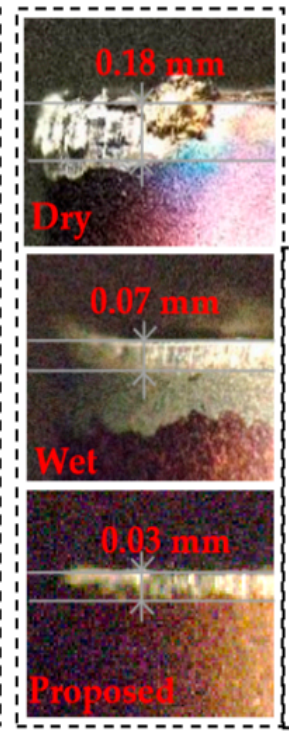

(b1) At cutting volume:

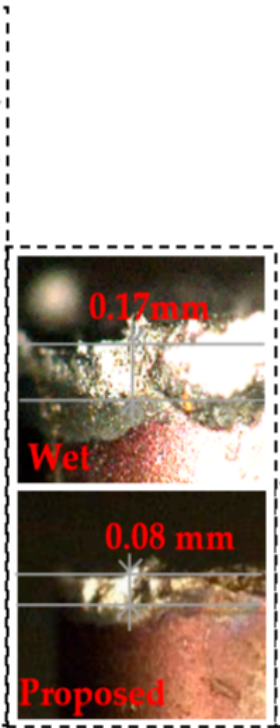

(b2) At cutting volume: $9600 \mathrm{~mm}^{3}$

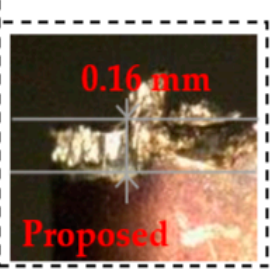

(b3) At cutting volume: $24000 \mathrm{~mm}^{3}$

Figure 5. Photographs of (a) the generated chip using multiple cutting methods and (b) tool wear at their tool-life limit (Wet cutting pressure: $8 \mathrm{MPa}$, proposed system pressure: $20 \mathrm{MPa}$ ).

\section{Conclusions}

The results of this study are summarized as follows:

(1) It was concluded that a coolant delivery method that consists of machining a hole at the tool tip from which high-pressure coolant is supplied achieves an improved tool-life. Here, given that coolant was directly supplied between the tool rake face and the workpiece, heat generation during the machining of difficult-to-machine materials can be suppressed to a certain extend.

(2) From intermittent bended sections found in the generated chip it was concluded that the high-pressure coolant pushes the chip from the bottom and effectively reduces the frictional heat generation over the rake face. 
(3) Coolant can be supplied between the tool rake face and the workpiece by devising a high-pressure coolant delivery method as observed in (1) and, (2) while maintaining the tool hardness and integrity.

Author Contributions: I.T. conceived of the presented idea. I.T. and H.H. manufactured the experimental set-up, and experimented for evaluation of the proposed system. Two authors provided critical feedback and helped shape the research and manuscript.

Conflicts of Interest: The authors declare no conflict of interest.

\section{References}

1. Yamane, Y.; Amano, N.; Hayashi, K.; Narutaki, N. High speed machining of Inconel 718 with ceramic tools-Suppression of notch wear. J. Jpn. Soc. Precis. Eng. 1993, 59, 1815-1820. (In Japanese) [CrossRef]

2. Kitagawa, T.; Kubo, A.; Maekawa, K. Temperature and wear of cutting tools in high-speed machining of Inconel 718 and Ti-6Al-6V-2Sn. Wear 1997, 202, 142-148. [CrossRef]

3. Usuki, H.; Sato, K.; Furuya, S. High speed dry end milling of titanium alloys with coated carbide tool. J. Jpn. Soc. Precis. Eng. 2005, 71, 491-495. (In Japanese) [CrossRef]

4. Davim, J.P. Metal Cutting Technologies: Progress and Current Trends; Walter de Gruyter GmbH: Berlin, Germany, 2016; pp. 60-74, ISBN 978-3-11-044942-6.

5. López de Lacalle, L.N.; Pérez-Bilbatua, J. Using High Pressure Coolant in the Drilling and Turning of Low Machinability Alloys. Int. J. Adv. Manuf. Technol. 2000, 16, 85-91. [CrossRef]

6. Suárez, A.; López de Lacalle, L.N. Effects of high-pressure cooling on the wear patterns on turning inserts used on alloy IN718. J. Mater. Manuf. Process. 2016, 32, 678-686. [CrossRef]

7. Pereira, O.; Rodríguez, A. Nozzle design for combined use of MQL and cryogenic gas in machining. Int. J. Precis. Eng. Manuf. Green Technol. 2017, 4, 87-95. [CrossRef]

8. Kaynak, Y.; Gharibi, A. Progressive Tool Wear in Cryogenic Machining: The Effect of Liquid Nitrogen and Carbon Dioxide. J. Manuf. Mater. Process. 2018, 2, 31. [CrossRef]

9. Rao, V. Advanced Modeling and Optimization of Manufacturing Processes: International Research and Development; Springer: London, UK, 2011; pp. 339-357, ISBN 978-0-85729-014-4.

10. Ito, Y.; Matsumura, T. Theory and Practice in Machining Systems; Springer International Publishing AG: Cham, Switzerland, 2017; pp. 71-89, ISBN 978-3-319-53900-3.

11. Horn GmbH. Internally Cooled Inserts for Grooving and Parting Off; Horn GmbH: Flensburg, Germany, 2017.

12. Takeyama, H. Cutting Process; Maruzen Inc.: Los Angeles, CA, USA, 1980; pp. 15-25, 30, 35-42, 64. (In Japanese)

13. Tanabe, I.; Junior, D.C.; Ye, H.S.; Tomioka, K.; Takahashi, S. Drilling technology using strong alkaline water with micro-bubble. Trans. Jpn. Soc. Mech. Eng. Ser. C 2013, 79, 748-758. (In Japanese) [CrossRef]

14. High Concentration of Micro Bubble Generator Type A-01 Specification. Available online: http:// www.idea-techno.com/pd/micro-bubble/naturan/kaatuyoukai-kounoudo.html (accessed on 1 June 2015). (In Japanese)

15. UNI-BTACH Catalog; E plan Inc.: Irvine, CA, USA, 2015; pp. 1-2. (In Japanese)

16. Shimohira, S. Material Science for Corrosion and Its Protection; AGNE Gijutsu Center: Tokyo, Japan, 1995; pp. 30-32, 255-257, 287-288.

17. Tanabe, I.; Ye, H.S.; Iyama, T.; Shibuya, M. Development of cutting technology in strong alkaline water. Trans. Jpn. Soc. Mech. Eng. Ser. C 2012, 78, 262-271. (In Japanese) [CrossRef]

18. Wakao, K.; Fujiwara, J.; Miyamoto, T. Cutting temperature and tool wear progress in turning of cemented carbid. In Proceedings of the JSPE Semestrial Meeting 2009, Hyogo, Japan, 21 September 2009; pp. 119-120. (In Japanese)

(C) 2018 by the authors. Licensee MDPI, Basel, Switzerland. This article is an open access article distributed under the terms and conditions of the Creative Commons Attribution (CC BY) license (http://creativecommons.org/licenses/by/4.0/). 